\title{
Numerical Simulation of Wind Impacts on Building Blocks: Towards Sustainable Architecture Strategies
}

\author{
Abdollah Baghaei Daemei ${ }^{1 *}$, Roya Aeinehvand ${ }^{2}$, Mostafa Kazemi ${ }^{3}$, Elham Mehrinejad Khotbehsara 4 \\ 1 Young Researchers and Elite Club, Rasht Branch, Islamic Azad University, Rasht, IRAN \\ ${ }^{2}$ Faculty of Architecture and Urban Planning, Central Tebran Branch, Islamic Azad University, Tehran, IRAN \\ ${ }^{3}$ Department of Architecture, Tabriz Branch, Islamic Azad University, Tabriz, IRAN \\ ${ }^{4}$ Department of Architecture, Rasht Branch, Islamic Azad University, Rasht, IRAN
}

*Corresponding Author: baghaei@iaurasht.ac.ir

Citation: Daemei, A. B., Aeinehvand, R., Kazemi, M. and Khotbehsara, E. M. (2019). Numerical Simulation of Wind Impacts on Building Blocks: Towards Sustainable Architecture Strategies. European Journal of Sustainable Development Research, 3(4), em0096. https://doi.org/10.29333/ejosdr/5859

Published: July 23, 2019

\begin{abstract}
The study of wind behavior around tall buildings is a critical issue in architectural and structural design. Therefore, Tall modern buildings are extremely sensitive to the wind. Thus, the assessment of wind loads to design these buildings is essential. Monitoring the wind, which is forcing extraordinary tall buildings is highly challenging. By looking at recent constructions in Iran, it is obvious that despite the fact that constructing tall buildings is spreading, there is less concentration on environmental factors such as wind's aerodynamic. The purpose of this study is to introduce a theoretical framework. Hence, by using CFD simulation, investigating on wind speed in various regions of the tall-triangular building have been focused. Finally, Autodesk Flow Design 2014 software is utilized to present a CFD simulation of a building model with a triangular footprint, Rounded Corner aerodynamic correction, and Set-back aerodynamic form. These simulations have been looking forward to finding out about how can aerodynamic forms affect pressure zone reduction in buildings and reduce wind flow pattern in urban regions.
\end{abstract}

Keywords: numerical simulation, wind impacts, tall buildings, sustainable design, architecture strategies

\section{INTRODUCTION}

The optimization of the building shape is regarded as an effective solution to enhance the safety and responsiveness of tall buildings to severe winds. The aerodynamic design is aimed at solving the problem of optimizing tall buildings in order to improve the structural sustainability against winds. It can be argued that wind force has a decisive role in the design of the tall buildings, even more important than the earthquake loads in some cases (Baghaei Daemei, et al., 2016; Parker and Wood, 2013). Approaches to designing tall buildings in order to control the vibrations induced by wind force can be divided into three main groups: architectural design approach, structural approach, and mechanical approach. From the structural design viewpoint, the tall buildings are more vulnerable to earthquake and wind loads induced by lateral forces than low-rise buildings due to their height (Baghaei Daemei et al., 2018; Günel and Ilgin, 2014). On the one hand the architectural aerodynamic design aims to reduce "wind effect" on the building. Also, they try to avoid the vortices generated in lower floors, sidewalls and the back of building (ACI SP-97, 1989). Broadly talking, wind imposes force on the buildings in three different ways including the force on wind flow, the force perpendicular to the wind flow, and torsional force. Winds always act horizontally and from the structural viewpoint, they exert a force, referred to as drag force, to the tall buildings. The drag coefficient is also an important parameter in their structural design. Traditionally, designers rely upon the 
results of wind tunnels and the experiments to estimate the drag coefficient. But, this process is both expensive and time-consuming to use. So, CFD simulation can be applied to assess building models.

Taking aerodynamic design and form optimization into consideration may have various consequences including lighter structural weight of the buildings, more appropriate response of the buildings to the wind, and consequently, lower stress for residents as well as attention to wake regions and correct layouts of the neighboring buildings. The present study aims to simulate different models of tall buildings and to explore them aerodynamically. We consider set-back, tapered, and helical (twisted) aerodynamic forms as well as aerodynamic modifications including chamfered, rounded, and recessed corners for the control of wind force applied to tall buildings. To this end, numerical simulation of the wind tunnel was employed to assess and compare the drag force exerted on 29 model buildings. The objective of the study was to optimize the aerodynamic shapes under the influence of wind force. Before proceeding, it's best to make the project's relationship to a sustainable design a little clearer. According to McLennan (2004) the intention of sustainable design is to "eliminate negative environmental impact completely through skillful, sensitive design". Manifestations of sustainable design require renewable resources, impact the environment minimally, and connect people with the natural environment. Sustainable architecture is the design of sustainable buildings. Also, new sustainable solutions for urban planning problems can include green buildings and housing, mixed-use developments, walkability, greenways and open spaces, alternative energy sources such as solar and wind. It's very clear that wind has always been a concern for designers as a very influential factor in sustainable design. But the wind does not just focus on wind turbine or natural ventilation. This article aims to give a more special look over the wind in urban environments.

\section{LITERATURE REVIEW}

Aerodynamic optimization of buildings has been subject to extensive studies. Davenport (1991) is one of the pioneers who focused on building aerodynamics. He examined the impacts of building shape using aerodynamic model tests (Davenport, 1971). As tall buildings flourished in the 1990s, more research was conducted on the modification of building corners by a potential decrease in aerodynamic forces (Dutton and Isyumov, 1990; Kareem et al., 1999; Kwok, 1988; Tamura and Miyagi, 1999). Tamura's group performed comprehensive wind tunnel experiment for multiple building configurations, e.g. the basic models (square, circular, rectangular, and elliptic), modified corner models, twisted models, Slotted models and combined models (Tamura et al., 2013; Tanaka et al., 2012). These data are not only useful for preliminary designing but they are also an invaluable source for further studies on building aerodynamics. Hayashida and Iwasa (1990) studied the aerodynamic shapes and their impact on vortexes for tall buildings. They explored eight different forms with equal hypothetical sizes of 600 $\mathrm{m}$ and equal densities of $125 \mathrm{~kg} / \mathrm{m}^{3}$. The results of computer simulation provide information about aerodynamic behavior and the impact of the vortex on the studied shapes for tall buildings (Hayashida and Iwasa, 1990). In addition, Dutton and Isyumov (1990) performed a similar study to reduce the motion of tall buildings using aerodynamic treatments. They focused on the use of openings in the building as the aerodynamic approach. The results revealed that the introduction of opening or gap could reduce the frequency of wind-induced vibrations in the building by about 15 percent (Dutton and Isyumov, 1990). Kawai (1998) worked on the effects of corner modifications on aero-elastic instabilities of tall buildings with a focus on the square building model. They found that among three states of corner roundness, cut and recession, roundness was at first the most effective against the wind in square cross-section. The next records indicated that when $\mathrm{b} / \mathrm{B}$ ratio, i.e. the rate of recession and cut, is 0.05 percent, it can be much better for the square cross-section (Kawai, 1998). In the next year, Tamura and Miyagi (1999) investigated the impact of turbulence in aerodynamic forces on square shape with aerodynamic modifications in corners. They used three models: perfect square, cut corner, and chamfered corner. Their results showed that cut and chamfered corners could mitigate the drag force as well as the wake region (Tamura and Miyagi, 1999). Kim and Kanda (2010) attempted to characterize the aerodynamic forces and the pressure on square plan buildings with height variations. They modeled a building with square plan tapered and set-backed at height so that they were tapered by 5 percent in the set-backed model and by 10 percent in the tapered model. It was reported that by tapering and set-back, the drag force and vibrations could be reduced. Also, it was revealed that the set-backed model could reduce the coefficients by about 40 percent as compared to the tapered model (Kim and Kanda, 2010). In another study, Kim et al. (2011) explored wind motion in tall buildings with a varying square plan with height. They introduced two tapered states and one set-back state versus the square state. The results showed that the set-back and tapered models had smaller torsional acceleration than the square state (Kim et al., 2011).

The aerodynamic design of tall buildings has been viewed from different perspectives. Studies have also been carried out on the coefficient of wind pressure in tall buildings. The impact of wind on the pedestrian level has been subject to investigations, too. Macêdo Wahrhaftig and da Silva (2017) examined the drag coefficient using computational fluid dynamic (CFD) simulation on a building with the height of $>93 \mathrm{~m}$. They stated that the 
Table 1. Configuration and specifications of wind tunnel boundary conditions

\begin{tabular}{|c|c|c|c|c|c|c|c|c|}
\hline \multirow{2}{*}{$\begin{array}{c}\text { Mesh size } \\
(\%)\end{array}$} & \multirow{2}{*}{ Status } & \multirow{2}{*}{$\begin{array}{l}\text { Time } \\
\text { (s) }\end{array}$} & \multirow{2}{*}{$\begin{array}{l}\text { Analysis } \\
\text { type }\end{array}$} & \multicolumn{3}{|c|}{ Wind tunnel size (m) } & \multirow{2}{*}{ Color } & \multirow{2}{*}{$\begin{array}{l}\text { Wind speed } \\
(\mathrm{m} / \mathrm{s})\end{array}$} \\
\hline & & & & Length & Width & Height & & \\
\hline 150 & Stabilized & 30 & $3 \mathrm{D}$ & 1300 & 300 & 300 & Standard & 10 \\
\hline
\end{tabular}

application of CFD can effectively simulate the drag force and wind-induced forces that are along with the fluid flow. It can also simulate the behavior of vortexes (Macêdo Wahrhaftig and Silva, 2018). Few studies have been carried out in Iran. For instance, Baghaei Daemei (2017) performed a thesis on the design of an appropriate model for tall buildings with a focus on environmental parameters in the template and humid climates. They investigated 16 building models to reduce wake region and 24 building models to reduce drag force. Also, they tried to provide designing techniques. The results showed that the form with foot-print, chamfered corners, and the tapered aerodynamic form could be the best shapes for the tall buildings in the studied climates (Baghaei Daemei, 2018).

\section{MATERIALS AND METHODS}

We applied the Autodesk AutoCAD 2014 software to model the samples and the Autodesk Flow Design 2014 software to simulate computational fluid dynamic (CFD). The wind speed was set at $10 \mathrm{~m} / \mathrm{s}$, and the simulation resolution (Mesh size) was set at 150\% for better display of the flow. Wind flow was studied in the 3D form in order to evaluate the drag force. According to Tamura et al. (2013), the specifications of the wind tunnel range was set at X: 49B, Y: 25B, and Z: 24B (Table 1).

The proportions of the models are 1/7 H/B. To validate the Autodesk Flow Design software, Autodesk Firm conducted a study entitled Flow Design Preliminary Validation Brief (2014) as a wind tunnel experiment and compared it with the ANSYS Fluent software. Then, their results were compared with the numerical simulations by Flow Design. The results showed an error deviation of about 6 percent between this software and the empirical testing and the numerical simulation, proving the validity of the software. The building was supposed to have a height, $\mathrm{H}$, of $150 \mathrm{~m}$ (about 50 stores) and a width, $\mathrm{B}$, of $25 \mathrm{~m}$. The edited proportions size was considered to be $1 / 10 \mathrm{~b} / \mathrm{B}$ in chamfered, recessed, and rounded corner models (Günel and Ilgin, 2014). Moreover, Baghaei Daemei et al. (2019) conducted a study entitled "Study on wind aerodynamic and flow characteristics of triangular-shaped tall buildings and CFD simulation in order to assess drag coefficient" in which CFD simulation was carried out by Autodesk Flow Design 2014. The purpose of this study is first to introduce a theoretical framework and simultaneously express basic aerodynamic studies.

\section{SHAPE OPTIMIZATION OF TALL BUILDINGS}

\section{Aerodynamic Methods for Architectural Designing}

Since aerodynamic behavior is, in general, of importance in tall, flexible buildings, aerodynamic design can play an important role in mitigating the impact of wind on tall buildings (Ali and Armstrong, 1995; Holmes, 2001; Irwin, 2009; Irwin and Baker, 2006; Irwin et al., 2008; Scott et al., 2005). Wind-induced responses of tall buildings can be reduced by aerodynamic design and modifications based on changing the flow and breaking the pattern of wind affecting the buildings. Design-based aerodynamics can be divided into 'aerodynamic architectural design' and 'aerodynamic architectural modifications' with their respective subcategories. Aerodynamic architectural design should be considered along with such issues as 'building orientation', 'aerodynamic form', 'plan variation', and 'aerodynamic top' as parts of the initial designs (Baghaei Daemei et al., 2019; Günel and Ilgin, 2014).

\section{Aerodynamic Top}

The approach to making the aerodynamic top is based on creating an aerodynamic form in upper parts of the building so as to mitigate the impact of wind on the building progressively. Also, in very tall buildings, wind flow should be directed towards its top (Baskaran and Kashef, 1996). In addition to transferring the parallel winds, this dynamic property can cause the building to respond appropriately to winds with perpendicular and twisted directions (by mitigating the vortex-induced turbulence of the wind) (Kikitsu and Okada, 2003). The optimal position for creating top aerodynamic is suggested to be between 80-90 percent of the building height (Taranath, 2005). Various buildings have been designed accordingly.

\section{Aerodynamic Forms}

The use of aerodynamic forms (Figure 1) is an effective way to reduce the wind load on the buildings. It is known that the cylindrical, elliptic, tapered and helical shapes are more efficient than the other shapes. The wind load is 20 percent smaller for the buildings in circular design form as compared to the buildings with rectangular 


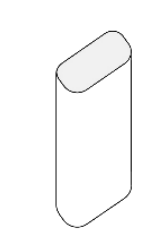

Soften corners
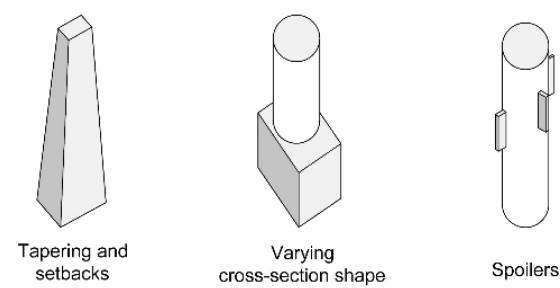

Spoilers

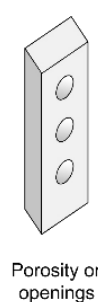

Figure 1. Strategies to reduce vortex effect

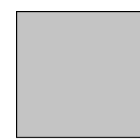

Sharp

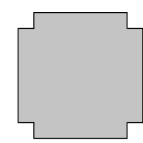

Recessed

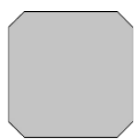

Cut

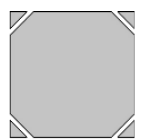

Sloted

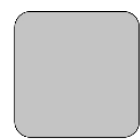

Rounded

Figure 2. Changes in the corners of the geometric shapes

plan form (Taranath, 2005). Buildings with elliptic form have similar behavior to circular buildings. The wind load can be lower by as high as 27 percent in buildings with elliptic form (Schueller, 1977).

\section{Geometry Variations in Corners}

The general shape of a building can play a major role in reducing the vortex as well as the aero-elastic effects. Architectural variations will decrease the effect of wind on the building to a great extent. These variations are applied to the corners of the buildings and provoke a more appropriate aerodynamic response when compared to sharp-corner buildings. The proper selection of the building shape and the introduction of suitable aerodynamic changes may reduce the wind motion or may change its pattern around a building. Therefore, extensive research has been performed on aerodynamic characteristics and the response of the buildings to wind (Amin and Ahuja, 2010; Ilgin and Günel, 2007; Kareem and Tamura, 1996; Kwok and Bailey, 1987; Melbourne and Cheung, 1988; Miyashita, 1993; Xie, 2012) (Figure 2).

\section{Corner Softening}

It is a very common practice to chamfer and soften the corners of rectangular or square-shaped buildings and set-back them. The amount should be for about 10 percent of the building width. This technique was tested in a wind tunnel test on Taipei 101 building whose height is $509 \mathrm{~m}$. The results showed 25 percent lower wind-induced force (Ilgin and Günel, 2007; Xie, 2012).

\section{Set-backed and Tapered Forms}

In this practice, the cross-section of the building is higher at lower floors and it is reduced progressively with the height. Since wind is faster at higher points, this technique reduces the wind-exposed area of the building, reducing wind impact on the building. The technique has been used for Burj Khalifa with $828 \mathrm{~m}$ architectural height (Parker and Wood, 2013).

\section{Geometric Changes in the Cross-section of the Shapes}

As the cross-section shape changes at the height, the frequency of wind impact changes. Since buildings have different geometries at the height, the vortexes have different properties at the height too and they will be less sensitive to wind. A good example is the Tower of Shanghai with the height of $632 \mathrm{~m}$ and rounded-corner triangular cross-section. In addition to gradual decrease, its angle is changed by $120^{\circ}$ as one moves from bottom to top. So, wind impact is reduced at height by introducing different shapes and widths. Data reveals $\sim 15$ percent lower wind load (Xie, 2012).

\section{WIND TUNNEL SIMULATION ON TALL BUILDING}

There are different software to assess dynamic behaviuor of wind in the urban areas by simulations. In the novel mechanic sciences this kind of calculation (calculating the wind behavior in the form of mathematical models), are known as CFD. Figure 3 illustrates a modeled shape with a triangular footprint, rounded corner correction, and set-back aerodynamic form. 


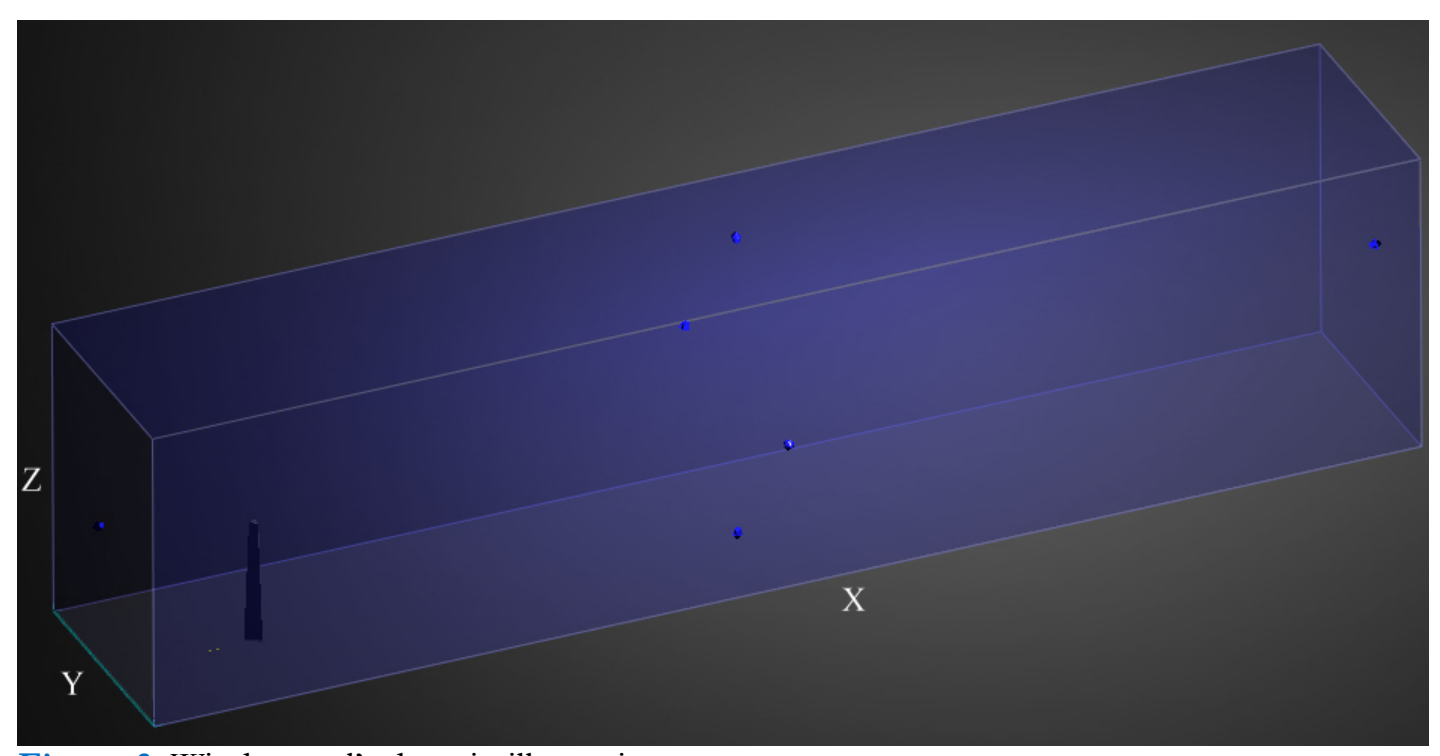

Figure 3. Wind tunnel's domain illustration

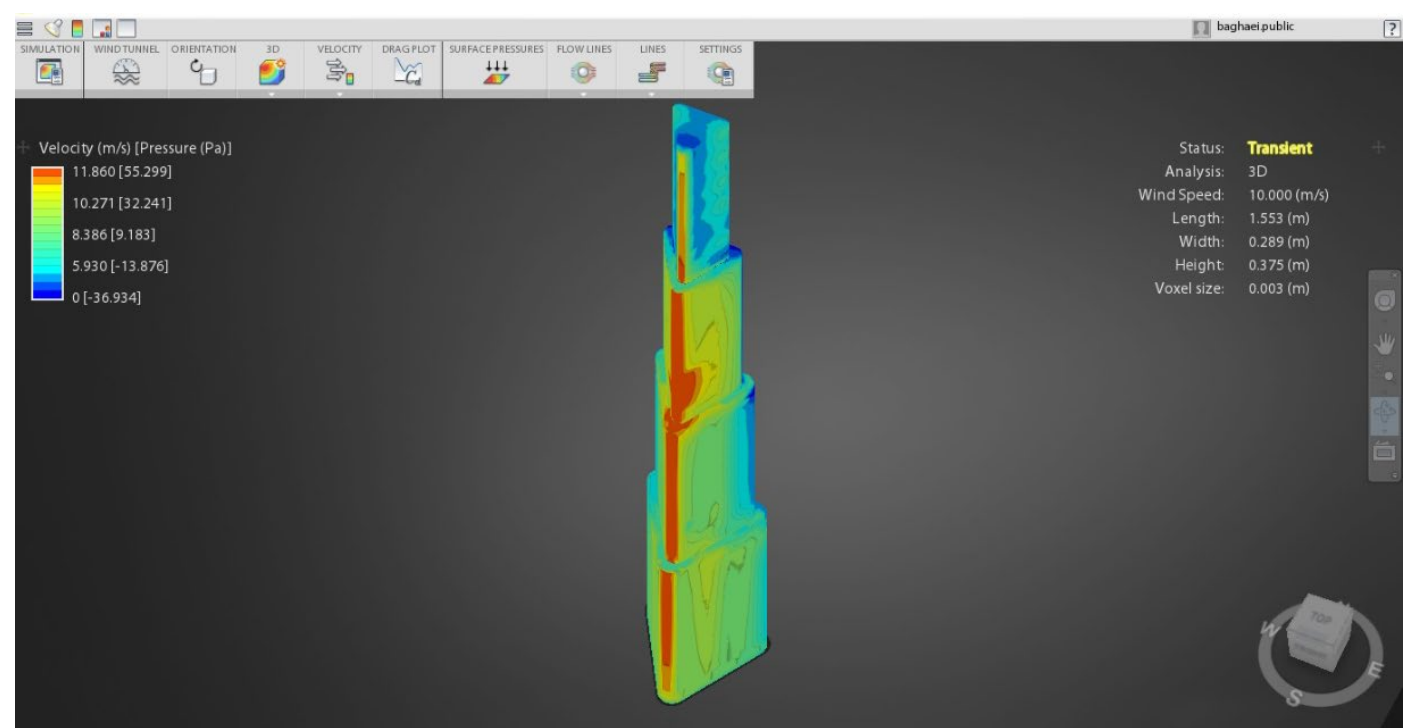

Figure 4. High-pressure and low-pressure nodes in a building model

According to Figure 3, it's necessary to initiate CFD simulations by defining a boundary layers (wind tunnel) as well as boundary condition in the software. This is due to provide a simulation accurate behavior of the wind flow and let the viscosity create natural friction which leads to a reduction in speed at the boundary layers. Typically, the size of the wind tunnel defines by environmental key factors. Figure 4 shows the pressure nodes on the building model.

Base on Figure 4, high-pressure nodes are highlighted by red color and the blue color shows low-pressure nodes. Generally, the side which is fronting to wind has a positive pressure and the other side has a negative pressure. The surface facing the wind is known as the wetted area (Figure 5). 

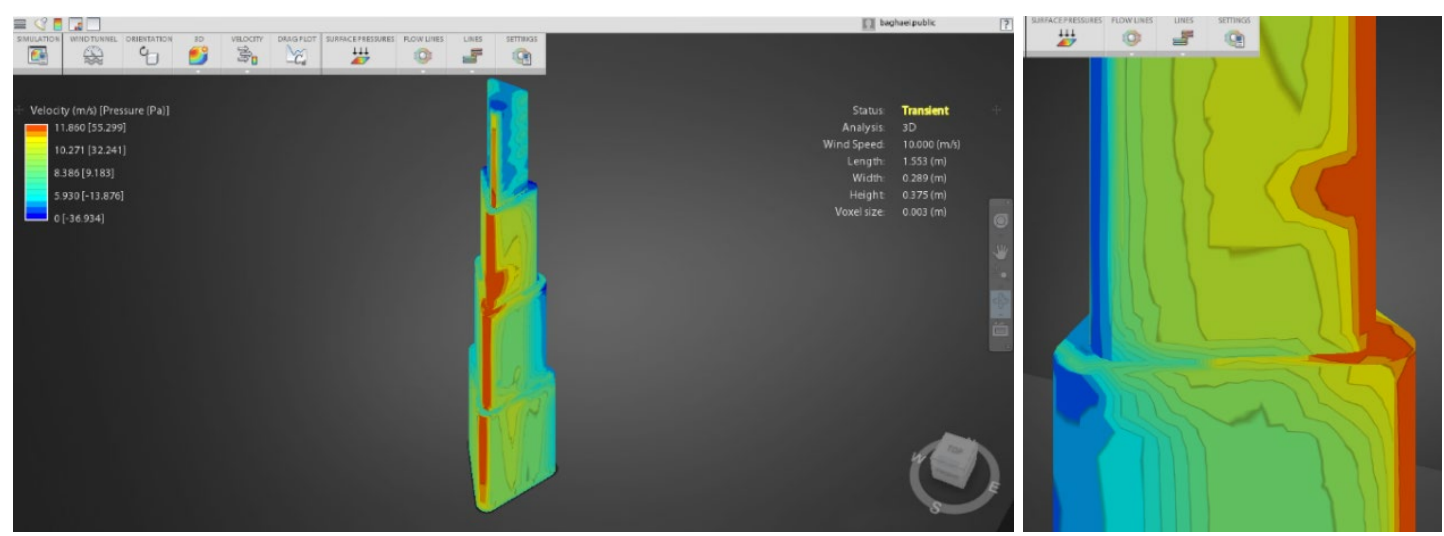

Figure 5. Wetted area in a building model, author

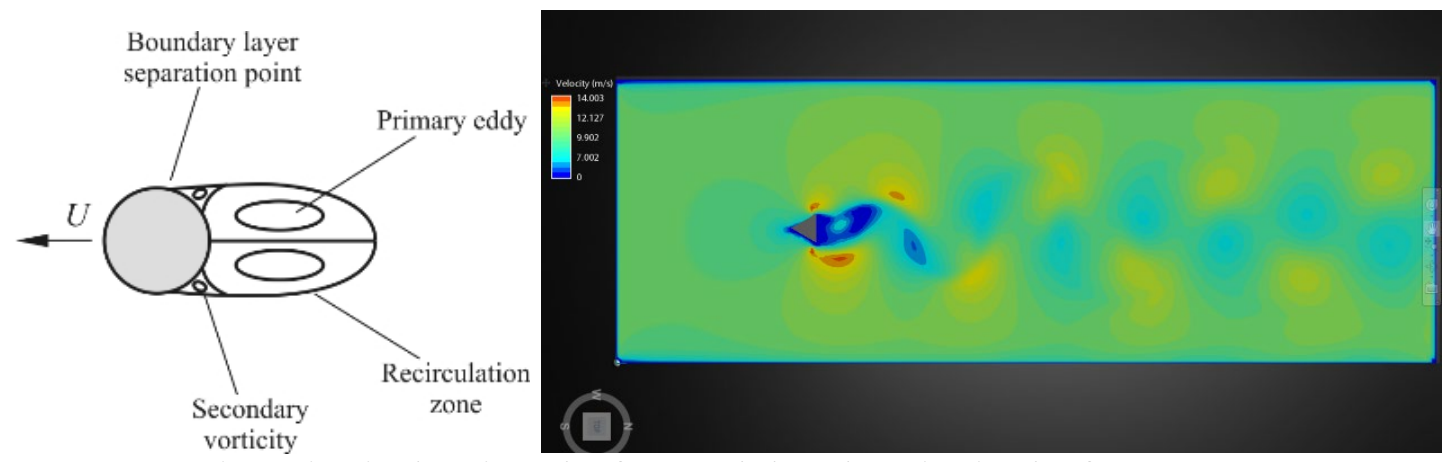

Figure 6. Wake region in the triangular form and shear layer in circular form

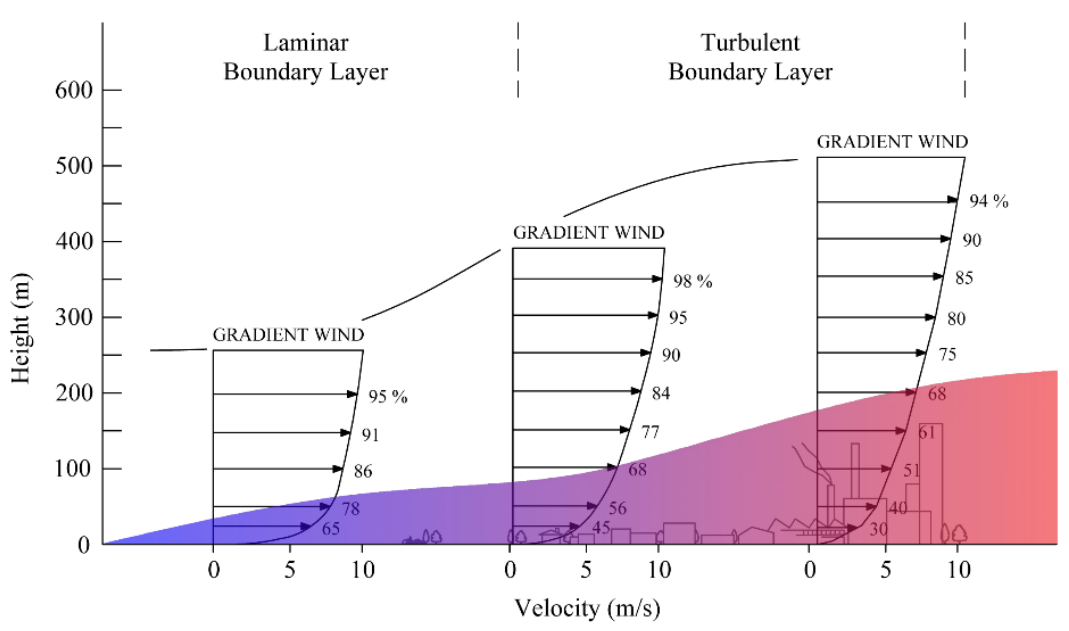

Figure 7. The boundary layer in urban spaces (Baghaei Daemei, 2019)

Despite the wind facing surface in Figure 8 which is colored by red has the most pressure, the area of this surface is small and it is based on the aerodynamic design of its form. Thus, aerodynamic forms have an ability to conduct least wind threat in the buildings. Controversy to this, they prevent the changes in wind flow patterns in urban environments which can make the neighboring buildings being under wind shear or wake region (Figure 6).

\section{WIND EFFECTS ON BUILDING BLOCKS}

\section{Urban Boundary Layer}

In physics and fluid mechanics, a boundary layer is an important concept and refers to the layer of fluid in the immediate vicinity of a bounding surface where the effects of viscosity are significant. In the Earth's atmosphere, the atmospheric boundary layer is the air layer near the ground affected by diurnal heat, moisture or momentum transfer to or from the surface. On an aircraft's wing the boundary layer is the part of the flow close to the wing, where viscous forces distort the surrounding non-viscous flow. 


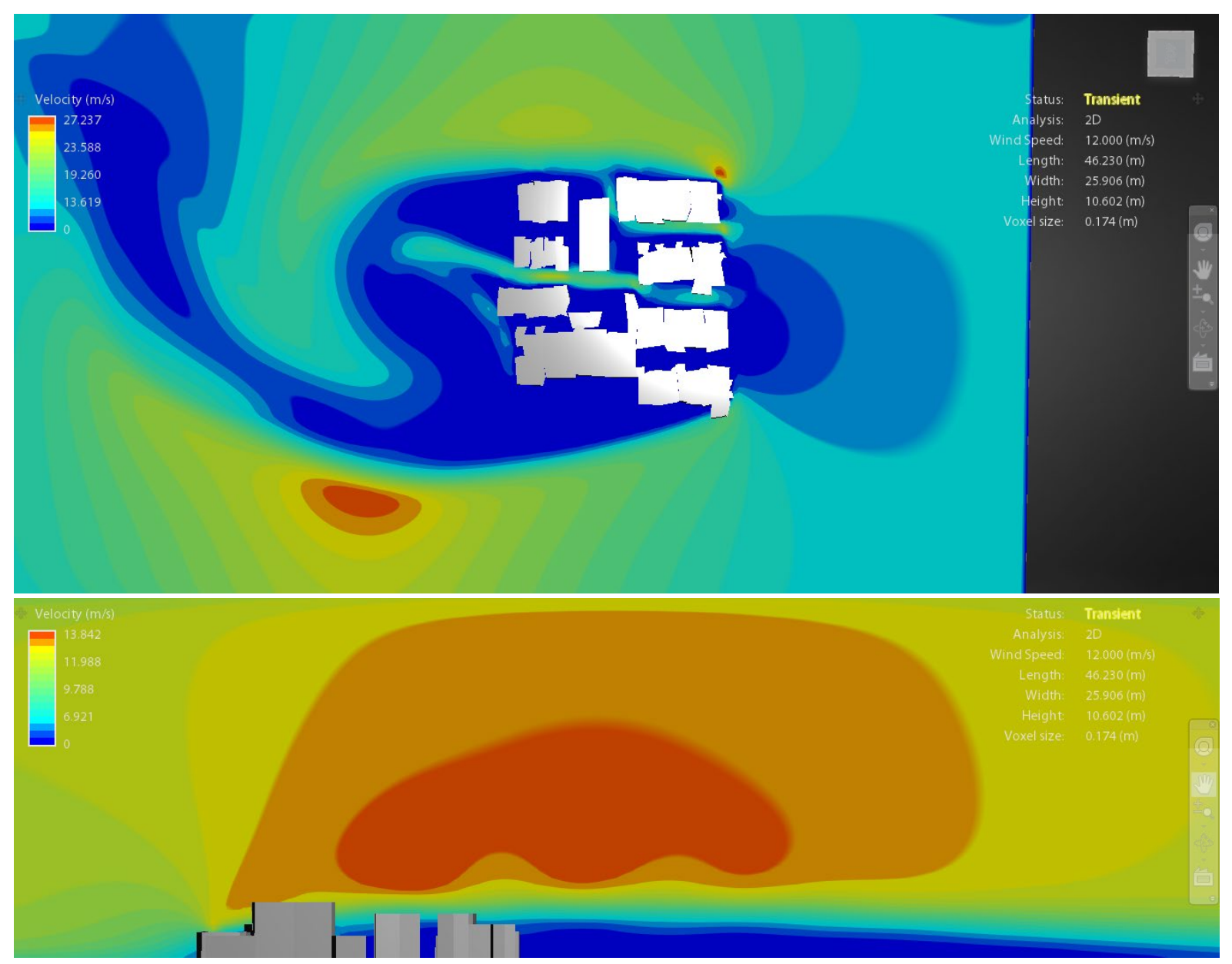

Figure 8. The simulation results of the wind on the pedestrian level (Plan and Elevation mode) (Simulated by authors)

Wind movement is usually horizontal and has a lower vertical behavior. However, in urban spaces, the effect of "topography" on wind movement will be affected. Since the Earth's surface is uneven, due to frictional properties, wind velocity is reduced to near ground level. With the reduction of topography and roughness on the air flow, the friction properties decrease as the surface gradients, so that from a height of a kilometer to the next, its effect is very low and can be neglected (Baghaei Daemei, 2017). The concept of the boundary layer was first proposed by Ludwig Pruntel in 1904 (Arakeri and Shankar, 2000).

\section{Simulation of the Wind in Urban Blocks}

The second part of the simulation was carried out in the form of a hypothetical building block complex. The wind speed was considered to be about $10 \mathrm{~m} / \mathrm{s}$. The elevation of the cross section was evaluated in the Autodesk Flow Design software in a Plane at a height of $10 \mathrm{~m}$ from the ground. In the following, simulation and evaluation of wind flow behavior are discussed. The height of these buildings varies from three to six floors. Specifications relating of the wind tunnel factor are presented in the section of the research methodology. This part of the study aims to explore wind flow characteristics in relation to human comfort at pedestrian level wind in urban spaces, through a numerical simulation. According to Baghaei Daemei (2019) provided lists a range of comfort classes based on wind speeds and limiting criteria. These classes attempt to quantify pedestrian comfort assuming suitable attire. They only consider wind speed and do not account for other weather conditions such as temperature and humidity. On this basis, acceptable wind speed for Sitting, Standing and Walking are $3.9 \mathrm{~m} / \mathrm{s}, 6.1 \mathrm{~m} / \mathrm{s}$ and $8.3 \mathrm{~m} / \mathrm{s}$ respectively. Figure 8 shows the wind flow behavior through building blocks.

Figure 8 shows the wind behavior at pedestrian level. The blue spectrum is a wind speed of less than $1 \mathrm{~m} / \mathrm{s}$. This phenomenon is consistent with the factors of sustainable development. Because at first the remaining the heat within the urban spaces and creates the phenomenon of urban heat island (UHT). Also, the amount of pressure and wind speed required to use buildings as natural ventilation is not provided. But if the wind speed exceeds a certain amount, it will lead to disomfort for the citizens (Figure 9). 


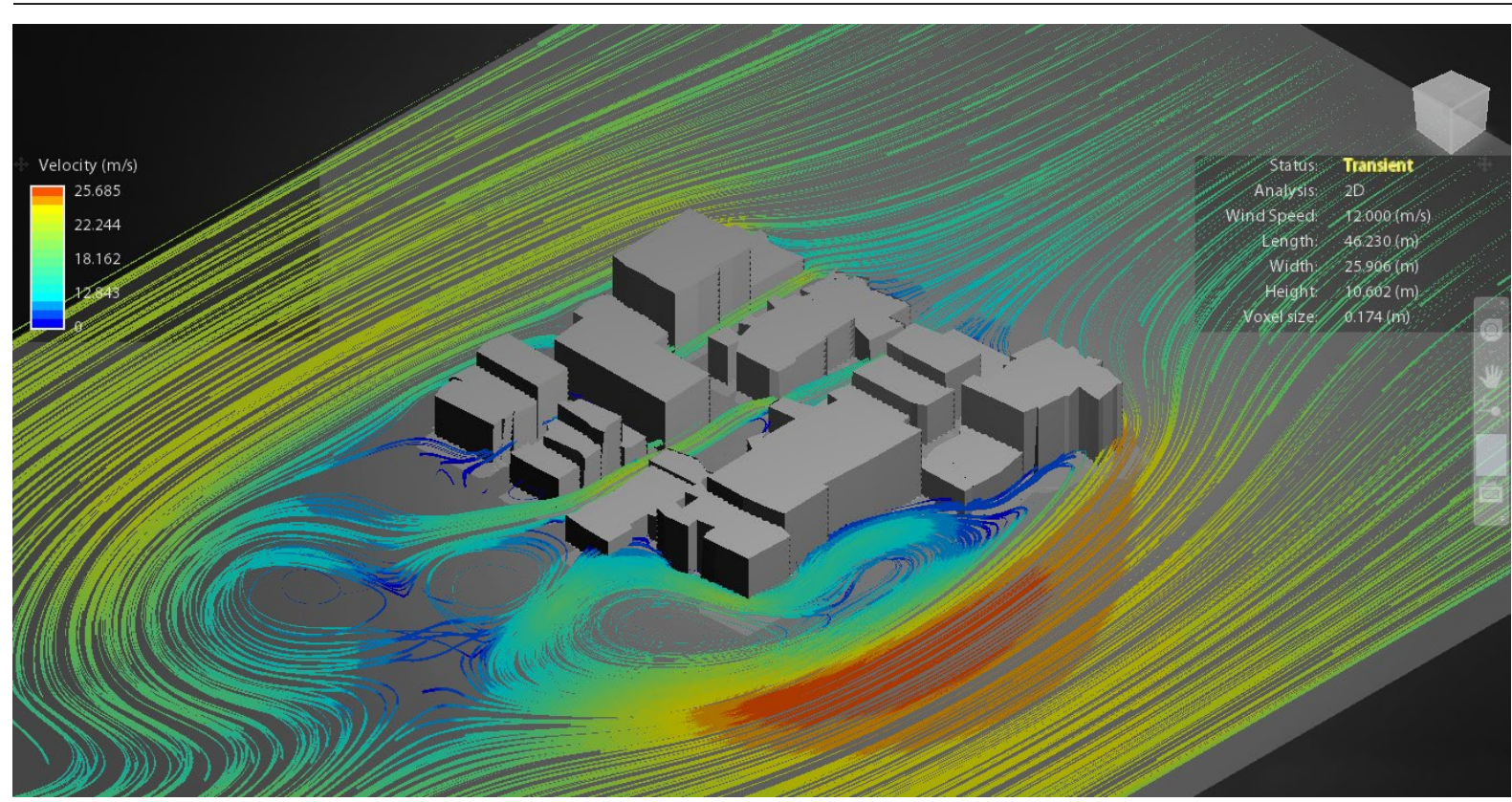

Figure 9. Wire frame mode of the simulation results of the wind on the pedestrian level (Plan mode) (Simulated by authors)

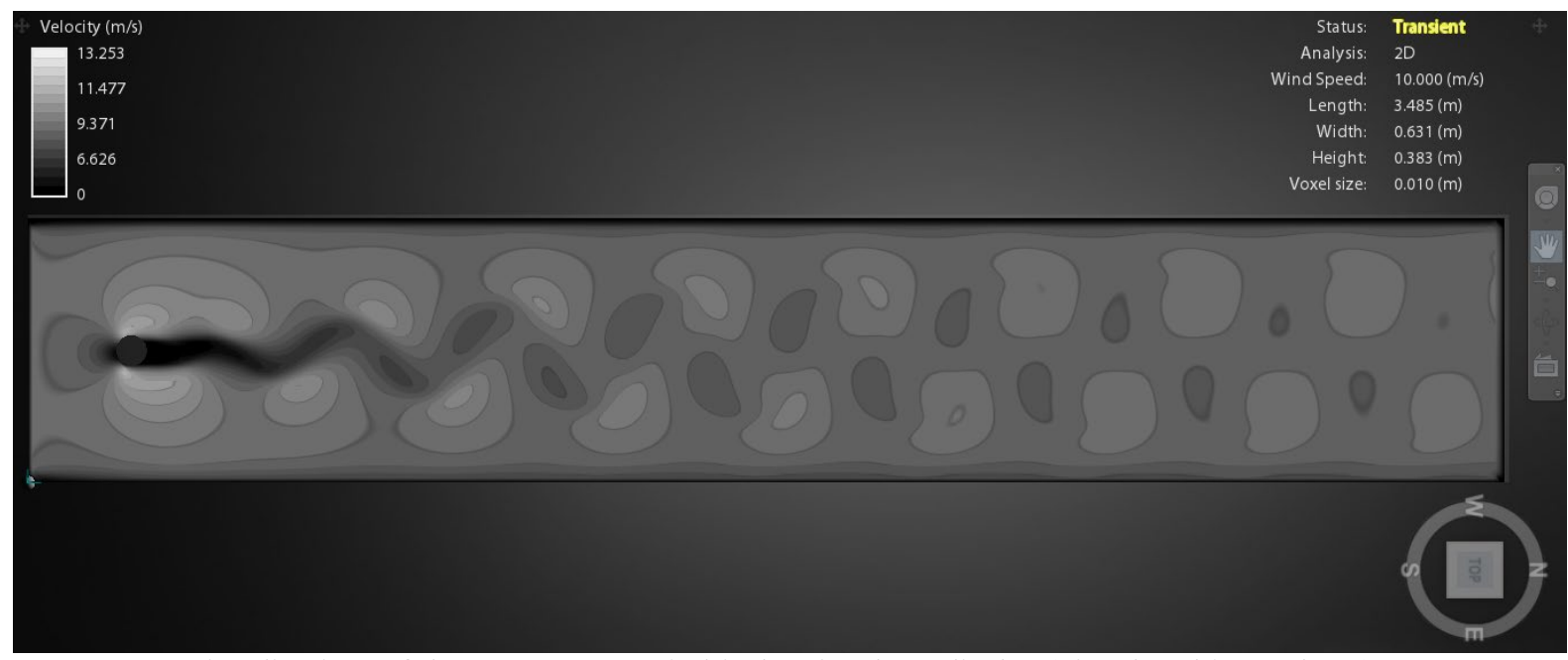

Figure 10. Visualisation of the vortex street behind a circular cylinder (Simulated by authors)

According to Figure 9, it was observed that in the wind flows around the buildings and when entering into the urban spaces, has a speed of about 10 to $15 \mathrm{~m} / \mathrm{s}$. As the simulation results showed that vortices are being made around the building. The following results were obtained there are vortices around the building. This phenomenon is called "shear layer" that usually provided to as wind gradient, is a variation in wind flow velocity and orientation over a relatively short distance in the urban environment. If the range of these shear layers is increased, it will create a turbulent model of wind that will create Vertex Stretch phenomenon behind the building. In fluid dynamics, a Kármán vortex street is a repeating pattern of swirling vortices, caused by a process known as vortex shedding, which is responsible for the unsteady separation of flow of a fluid around blunt bodies. It is named after the engineer and fluid dynamists Theodore von Kármán (Karman, 1963) (Figure 10).

\section{CONCLUSION}

According to the state of the art of this study, it has been clarified that the wind aerodynamic consideration is one of the crucial factors in the architectural, structural, and mechanical design of the buildings. Disregarding this, will individually cause high pressures on the structure of the buildings and also will change the wind flow pattern in urban areas as well as causing turbulent wind flows which result in feeling discomfort by citizens. Furthermore, a design without aerodynamic consideration could be a serious threat for neighboring buildings since these buildings will be under wake region range and they would not be able to get advantages of natural ventilation in most times of the year. From CFD simulations we could find out how set-back aerodynamic form can reduce the 
applied pressure on the building in parallel to knowing how much Rounded-Corner aerodynamic corrections can cut down the amount of vortex region. Hence, we recommend for the future research to more precisely study on means of utilizing aerodynamic sciences in the architectural designs and urban development studies.

Moreover, windbreak can be used to protect the pedestrian zone in an urban space from high wind speeds and turbulence and can be both solid structures (buildings, walls, etc.), or permeable structures (vegetation, open fences, etc.). Solid windbreaks can give good shelter close to the structures. But, tend to create high wind velocities and turbulence further away. Thus, it is most cases it is better to use permeable windbreaks. Vegetation is a very effective windbreaker as branches and leaf will slow down the wind without creating a lot of turbulence. Studies have shown that medium close plant belts give the best and most uniform shelter.

\section{REFERENCES}

ACI SP-97 (1989). Analysis and Design of High-Rise Concrete Buildings, U.S.A.

Ali, M. and Armstrong, P. (1995). Architecture of Tall Buildings, Council on Tall Buildings and Urban Habitat Committee (CTBUH), New York: McGraw-Hill Book Company.

Amin, J. A. and Ahuja, A. K. (2010). Aerodynamic modifications to the shape of the buildings: a review of the state-of-the-art. Asian journal of civil engineering (building and housing), 11(4), 433-450.

Arakeri, J. H. and P. N. Shankar (2000). Ludwig Prandtl and boundary layers in fluid flow. Resonance, 5(12), 48-63. https://doi.org/10.1007/BF02840395

Baghaei Daemei, A. (2017). Designing a Model of Affordable Housing in Tall Building with a focus on the use of Environmental Factors in Humid Subtropical Climate - Roofing Rasht, Thesis for: Master DegreeAdvisor: Seyed Rahman Eghbali, Islamic Azad University Branch of Rasht, Department of Architecture, Rasht, Iran. https://doi.org/10.13140/RG.2.2.25988.83841/2

Baghaei Daemei, A. (2019). Wind Tunnel Simulation on the Pedestrian Level and Investigation of Flow Characteristics around Buildings. Journal of Energy Management and Technology, 3(1), 58-68. https://doi.org/10.22109/jemt.2019.135527.1100

Baghaei Daemei, A., Ayoubi Mobarhan, S., Ansari Vaske, F. and Bahrami, P (2018). A review of tall buildings architectural design consideration and guiding principles (Case study: City of Toronto), Conference: International Interdisciplinary Conference "Russia and the East: the Interaction in Art"At: Russia, Moscow.

Baghaei Daemei, A., Khalatbari Limaki, A. and Safari, H. (2016). Opening Performance Simulation in Natural Ventilation Using Design Builder (Case Study: A Residential Home in Rasht). Energy Procedia, 100, 412-422. https://doi.org/10.1016/j.egypro.2016.10.196

Baghaei Daemei, A., Mehrinejad Khotbehsara, E., Malekian Nobarani, E. and Bahrami, P. (2019). Study on wind aerodynamic and flow characteristics of triangular-shaped tall buildings and CFD simulation in order to assess drag coefficient, Ain Shams Engineering Journal. https://doi.org/10.1016/j.asej.2018.08.008

Baskaran, A. and Kashef, A. (1996). Investigation of air flow around buildings using computational fluid dynamics techniques. Engineering Structures, 18(11), 861-875. https:// doi.org/10.1016/0141-0296(95)00154-9

Davenport, A. G. (1971). The response of six building shapes to turbulent wind. Phil. Trans. R. Soc. A, 269, 385394. https://doi.org/10.1098/rsta.1971.0039

Dutton, R. and Isyumov, N. (1990). Reduction of tall building motion by aerodynamic treatments. Journal of Wind Engineering and Industrial Aerodynamics, 36, 739-47. https://doi.org/10.1016/0167-6105(90)90071-J

Flow Design Preliminary Validation Brief (2014). Available at: www.simhub.autodesk.com/resources/flowdesign-wind-tunnel-validation-brief

Günel, M. H. and Ilgin, H. E. (2014). Tall Buildings Structural Systems and Aerodynamic Form. First published, Routledge, Taylor \& Francis Group, New York. https://doi.org/10.4324/9781315776521

Hayashida, H. and Iwasa, Y. (1990). Aerodynamic shape effects on tall building for vortex induced vibration, Journal of Wind Engineering and Industrial Aerodynamics. Nos. 1-2(33), 237-42. https://doi.org/10.1016/0167-6105(90)90039-F

Holmes, J. D. (2001). Wind Loading of Structures. London: Spon Press. https://doi.org/10.4324/9780203301647

Ilgin, H. E. and Günel, M. H. (2007). The role of aerodynamic modifications in the form of tall buildings against wind excitation. METU JFA, 24(2), 17-25.

Irwin, P. A. (2009). Wind Engineering Challenges of the New Generation of Super-Tall Buildings. Journal of Wind Engineering and Industrial Aerodynamics, 97, 328-334. https://doi.org/10.1016/j.jweia.2009.05.001

Irwin, P. A. and Baker, W. F. (2006). The Burj Dubai Tower: Wind Engineering. Structure Magazine, 28-31.

Irwin, P. A., Kilpatrick, J., Robinson, J. and Frisque, A. (2008). Wind and Tall Buildings: Negatives and Positives. The Structural Design of Tall and Special Buildings, 17, 915-928. https:/ / doi.org/10.1002/tal.482

Kareem, A. and Tamura, Y. (1996). Mitigation of Wind-Induced Motions of Tall Buildings, Tall Building Structures: A World View. Council of Tall Buildings and Urban Habitat, Lehigh University.

(C) 2019 by Author/s 
Kareem, A., Kijewski, T. and Tamura, Y. (1999). Mitigation of Motion of Tall Buildings with Specific Examples of Recent Applications. Wind and Structures, 2(3), 201-251. https://doi.org/10.12989/was.1999.2.3.201

Karman, T. V. (1963). Aerodynamics: History and Analysis of Flight. USA: McGraw-Hill Book.

Kawai, H. (1998). Effects of corner modifications on aeroelastic instabilities of tall buildings. Journal of Wind Engineering and Industrial Aerodynamics, 74-76, 719-29. https:/ / doi.org/10.1016/S0167-6105(98)00065-8

Kikitsu, H. and Okada, H. (2003). Characteristics of Aerodynamic Response of High-rise Buildings with Open Passage, Proceedings of the CIB-CTBUH International Conference on Tall Buildings, Malaysia.

Kim, Y. and Kanda, J. (2010). Characteristics of aerodynamic forces and pressures on square plan buildings with height variations. Journal of Wind Engineering and Industrial Aerodynamics, 98(8-9), 449-465. https://doi.org/10.1016/j.jweia.2010.02.004

Kim, Y. C., Kanda, J. and Tamura, Y. (2011). Wind-induced coupled motion of tall buildings with varying square plan with height. Journal of Wind Engineering and Industrial Aerodynamics, 99(5), 638-650. https://doi.org/10.1016/j.jweia.2011.03.004

Kim, Y. M. and You, K. P. (2002). Dynamic response of a tapered tall building to wind loads. Journal of Wind Engineering and Industrial Aerodynamics, 90, 1771-82. https://doi.org/10.1016/S0167-6105(02)00286-6

Kwok, K. C. S. (1988). Effect of building shape on wind-induced response of tall buildings. J. Wind Eng. Ind. Aerodyn., 28, 381-390. https://doi.org/10.1016/0167-6105(88)90134-1

Kwok, K. C. S. and Bailey, P. A. (1987). Aerodynamic devices for tall building and structures, Journal of Engineering Mechanics. ASCE, 4(111), 349-65. https://doi.org/10.1061/(ASCE)0733-9399(1987)113:3(349)

Macêdo Wahrhaftig, A. and Silva, M. A. (2018). Citation for: Using computational fluid dynamics to improve the drag coefficient estimates for tall buildings under wind loading. The Structural Design of Tall and Special Buildings, 27(3), e1442. https://doi.org/10.1002/tal.1442

Melbourne, N. H. and Cheung, J. C. K. (1988). Designing for serviceable accelerations in tall buildings, 4th International Conference on Tall Buildings, Hong Kong and Hanghai.

Miyashita, K., Katagiri, J., Nakamura, O., Ohkuma, T., Tamura, Y., Itoh, M. and Mimachi, T. (1993). Wind induced response of high rise building: effects of corner cuts or opening in square building. Journal of Wind Engineering and Industrial Aerodynamics, 50, 319-28. https://doi.org/10.1016/0167-6105(93)90087-5

Parker, D. and Wood, A. (2013). The Tall Buildings Reference Book. First published, USA: Routledge, Taylor \& Francis Group. https:// doi.org/10.4324/9780203106464

Schueller, W. (1977). High-Rise Building Structures. New York: John and Wiley Sons Inc.

Scott, D., Hamilton, N. and Ko, E. (2005). Structural Design Challenges for Tall Buildings. Structure Magarine, 2, $20-23$.

Tamura, Y. and Miyagi, T. (1999). The effects of turbulence on aerodynamic forces on a square cylinder with various corner shapes. J. Wind Eng. Ind. Aerodyn., 83, 135-145. https://doi.org/10.1016/S0167-6105(99)000677

Tamura, Y., Kim, Y. C., Tanaka, H., Bandi, E. K., Yoshida, A. and Ohtake, K. (2013). Aerodynamic and response characteristics of super-tall buildings with various configurations, keynotes. In: Proceedings of the Eighth AsiaPacific Conference on Wind Engineering, Chennai, India. https://doi.org/10.3850/978-981-07-8012-8_Key-12

Tanaka, H., Tamura, Y., Ohtake, K., Nakai, M. and Kim, Y. C. (2012). Experimental investigation of aerodynamic forces and wind pressures acting on tall buildings with various unconventional configurations. J. Wind Eng. Ind. Aerodyn., 107-108, 179-191. https://doi.org/10.1016/j.jweia.2012.04.014

Taranath, B. (2005). Wind and Earthquake Resistant Buildings: Structural Analysis and Design, A Series of Reference Books and Textbooks (Editor: Meyer, M. D.), Department of Civil and Environmental Engineering, Georgia Institute of Technology, Atlanta, Georgia. https://doi.org/10.1201/9780849338090

Xie, J. (2012). Aerodynamic optimization in super-tall building designs, The Seventh International Colloquium on Bluff Body Aerodynamics and its Applications (BBAA7) Shanghai, China; September 2-6, 2012. 